\title{
Career Development and Contemporary Visual Artists: An Investigation of Cairns Australia
}

\author{
Crystal Williams
}

James Cook University, Cairns

\begin{abstract}
The purpose of this research was to identify key factors of relevance in relation to career development opportunities for contemporary visual artists in Cairns. Cairns is a tropical city in northeastern Australia with an energetic and creative visual arts community. In order to explore issues relevant to career development opportunities for a Cairns-based contemporary visual artist, interviews were held to examine the perceptions of key stakeholders within the arts community. These data were initially analysed by stakeholder groups, after which key themes were established and compared across the groups to identify similarities and differences. The results reveal contrasting views and the fact that there are numerous opportunities to create clearer pathways and opportunities for contemporary visual artists based in Cairns.
\end{abstract}

$\mathrm{T}$ he regional city of Cairns in far north Queensland has an active contemporary visual arts community. The city is home to various visual art related activities, such as artist-runinitiatives, art organisations, art associations, pop-up spaces, commercial galleries, a centre for contemporary arts, community run workshops, a tertiary education degree and collective groups. However, despite the vibrant activity, there is a lack of published research and knowledge about what issues or influences affect career development for contemporary visual artists in Cairns. Further, perceptions abound in the community in terms of the extent to which artists are able to develop a viable long-term career in Cairns. Hence this paper seeks to present a response to this gap in knowledge.

\section{Literature of Relevance}

Defining a contemporary artist is difficult as there are no defining trends, nor movements or dominant schools as there were in the past (Thompson 56). Furthermore, except for some suggestions that the temporal frame of what constitutes 'contemporary' appears to have emerged from the 1990s and early twenty-first century, after the modernists and postmodernists and still current today (Smith 325; Bishop et al. 46), what constitutes 'contemporary' is found to have no clear acceptance among scholars, curators, academics and artists of any specific time frame. Therefore, this paper adopts the basic definition that a contemporary visual artist is one who is currently practicing at this time.

The Australia Council states that since the first published report was released in 1983, there has been growing support from governments, business and other researchers for understanding artistic careers (1). Emerging research points to the fact that it is increasingly common for the career path of an artist to be protean, portfolio and/or boundaryless portfolio and/or boundaryless (Bridgstock, qtd in "Skills for Creative Industries Graduate Success" 11), non-linear forms of employment driven by the individual and subject to many influences. In many cases, artistic careers encompass multiple job holding, and are difficult to sustain fulltime income, as recognised in the report Multiple job-holding and artistic careers: some empirical evidence (Throsby and Zednik 11). 
Leading expert, Ruth Bridgstock who has published articles about the importance of artists being 'enterprising' or 'entrepreneurial' ("Not a Dirty Word: Arts Entrepreneurship and Higher Education" 181), is an authority in the field of artistic careers. Bridgstock identified that 'well-developed career management' skills or 'self-management skills' aid in successful employment for artists ("Skills for Creative Industries Graduate Success" 21). According to Bridgstock, in order to sustain an artistic career in the $21{ }^{\text {st }}$ Century, it is "increasingly insufficient to rely solely on technical expertise and creative ability;" social networking, being entrepreneurial and self-management skills were identified as integral for developing careers ("Not a Dirty Word: Arts Entrepreneurship and Higher Education" 181). Ultimately, there is very little academic research relevant to the career development of a Cairns-based contemporary visual artist. One of a few written publications found was a recent unpublished report by Youdell and Milledge ("Collective Future" 3) who revealed that the typical Cairns regional artist holds seasonal part-time employment and lacks specialized skills and education. On the other hand, Youdell and Milledge claim that survival relies heavily on the ability to sustain relationships and networks ("Collective Future" 3), a view echoing the work of Bridgstock ("Not a Dirty Word: Arts Entrepreneurship and Higher Education" 181; Bridgstock "Skills for Creative Industries Graduate Success" 11). The Youdell and Milledge report shows that opportunities for artists or arts workers are seasonal, because events and projects are temporal and year-by-year ("Collective Future" 3). Very few researchers have attempted to investigate relationships specific to regional contemporary visual arts markets, particularly looking at the factors of influence gatekeepers (Bystryn 391; De Roeper 53) hold in relation to artist careers in areas isolated from metropolitan galleries. Through the investigation into the roles played by key stakeholders within the contemporary arts community in Cairns, this study seeks to reveal some insights and influences.

\section{Methodology}

The research framework chosen for this paper is qualitative and relies on the social anthropology approach known as ethnography (Miles and Huberman 8). This method was chosen due to the focus on the personal perceptions from key stakeholders; to access the views of those on the ground directly involved in the contemporary visual arts sector in Cairns. Recorded interviews were determined to be the most appropriate method of collecting data for analysis. The paper focused on recording the interviews of key stakeholders within the Cairns visual arts community who were over 18 years of age and currently practicing or supporting the visual arts (paid or unpaid). In order to have a well-rounded interpretation of the Cairns visual arts community, the study sample included a broad selection of stakeholders, including:

- Two curators from an established organisation;

- An arts administrator from an established organisation;

- A university arts educator;

- A director of an established arts organisation;

- A director of an artist run initiative (small organisation);

- A member of the Regional Arts Development Fund;

- A representative of Arts Queensland;

- A member of the Cairns Visual Arts Association;

- A council arts worker;

- Four practicing contemporary visual artists; and

- A director of a commercial gallery. 
The interview transcripts were initially read as individual conversations, after which they were investigated question by question, in terms of all responses to each particularly area of inquiry. In time, it became clear that there were general patterns and themes.

\section{Results}

\section{Artists Living in Cairns}

The major inhibitor mentioned by Cairns-based artists related to cost - the cost of traveling to and from, and exporting works outside the region. According to some stakeholders, this distance, and therefore cost, prevented opportunities to exhibit in large metropolitan galleries or institutions. For instance, one artist stated: "The distance thing is a negative because you don't tend to apply for other opportunities in the larger centres because the [cost of] transport can be inhibitive..." (Ralph - Artist). Many stakeholders also referred to the inhibiting factor of no substantive aid to help regional contemporary visual artists in general, to overcome the costs incurred from sending work from such vast distances.

Cara (Artist) pointed out that without access to larger cities, artists were unable to reach an appreciative market. Cara said, "You can not charge what you would charge down south, people would just not pay it here." The isolation of living in Cairns appeared to limit this artist from networking with serious clients to make sustainable incomes.

Many artists felt that living in the environment and lifestyle of Cairns had both positive and negative influences on career development. For example Graham (Artist) felt that the positive factors were "mostly because of the tourism." However, the artist also thought the warmer climate had some negative influences. Graham felt "the downside has more to do with temperature" as the local "people are used to doing more outdoors types of things."

Despite the climate, most artists viewed the lifestyle in Cairns as a positive influence on their careers. Cairns' relatively small size meant there was smaller commuting distances, which could allow for more time to work on artistic practices. One artist summed up the positive influences in the comment:

The size of Cairns; It is easy to network, easy to meet people and it's easy to meet people with galleries... I have more time, if I lived in a big city I would be commuting one to two hours a day which would eat into my time (Cara - Artist).

In general, the distance from major cities meant increased costs, which then had a negative affect on opportunities to network. This limited the chances of exhibiting beyond Cairns to lucrative markets. On the other hand, the Cairns environment and lifestyle inspired artists and attracted tourists.

\section{Distribution, Access and Opportunities}

While comments from organisations and galleries on how they were distributing their information about opportunities varied to some extent, websites proved to be the most common method. Neal (Representative, Arts Queensland) stated, "our website is our information portal." 
Yet, despite their efforts with using a range of strategies, most stakeholders were unable to make a clear assessment as to which method was the most successful in reaching artists. Lisa (Curator), for example explained that she had lacked an understanding of "how artists were finding out about things" In addition, Richard (University Arts Educator) was also concerned that the methods of using social media were unreliable. Richard claimed, "a lot of services [in Cairns] are shifting away from print media and relying on social media, but I'm not sure how that works because there is so much media inside social media." The views of the artists revealed that information was being filtered through to them mainly by word of mouth and or through personal social media networks. Yet it would be difficult to say if methods such as 'word of mouth' were reliable sources.

Surprisingly, one issue that arose during the interviews was that a central hub for disseminating information (not just those of individual organisations) was lacking in Cairns. The lack of a central outlet providing information may be causing some disgruntlement, as there are some artists who believe the council or government funded organisations should be taking up the roles of disseminator and information hub. For instance, the Ralph (Artist) stated, "If there is an institution that is government funded then I think that they should be distributing the information... surely they could collate it?" However, the challenge is that some organisations in Cairns do not see themselves as the disseminators of information. Sam (Arts Administrator) argued, "We don't provide that information, that's not a service that we offer." Further, he did not believe that information dissemination should be the role of organisations.

Another issue relevant to distribution was that the artists perceived accessibility to opportunities as difficult. Ralph, who perceived himself as an established artist, described his frustration accessing space and rates the level of accessibility to exhibit in Cairns as "about $1 \%$." Ralph further added he had not seen applications to apply for a long time. Kirsty (Artist) described the level of accessibility as "very low" and Cara (Artist) and "assumed there was a massive amount of paperwork." Yet it is important to understand some other underlying factors. For example, Ethel, the director of a arts organisation described that her organisation became extremely selective and only offered a few invitations to those artists who were considered to be of an exceptional level and also 'fit' within the criteria (apart from the one wall which they offered as space to showcase emerging artwork). Ethel stated that her organisation "act as an arbiter for best quality contemporary arts" and "there are other opportunities for emerging artists and amateur artists or hobbyists to get involved in groups and get work shown in other venues."

Although it is important to have benchmarks and to encourage artists to develop, organisations' criteria appear to result in excluding some artists, particularly those in an early stage of their professional careers. Lucy (Member, Visual Arts Association) explains how members within her association were concerned that a variety of local group exhibitions were recently reduced at one government funded and further added, "what is happening now is the new director has gone in a new direction and she is trying to get in all exclusive exhibitions from down south."

Similarly, Neal (Representative, Arts Queensland) acknowledged that, "You have a Regional Art Gallery which is meant to be representing local artists but at the same time they are trying to maintain a level of visitations."

It is not surprising then, that galleries' and organisations' perceptions of the accessibility to their opportunities concurred with the artists' perceptions; they too perceived the 
opportunities to be difficult to access. Sam (Arts Administrator) stated "I think it is very difficult... we make it difficult for a reason." Sam explained the reasons for difficult applications are to seek out the serious artists from the non-serious ones. Yet Sam sympathized with the limited space artists are now faced.

Hence, the arts community is seeing a reduction in exhibition spaces for those artists that do not fit the levels of professionalism and do not align with the agendas of the organisations. Furthermore, due to the absence of a single disseminator of information or informational hub, distribution is segmented and the opportunities for career development are not appearing to successfully reach a broad range of artists.

\section{Relationships, Networks and Engagement}

In regard to relationships between organisations, views were mixed. On the one hand, Ethel (Director, Arts Organisation) felt that "relationships are productive and positive within the arts community." On the other hand, others had expressed a sense of conflict or lack of cohesion:

- "One of the first things I wanted to do was to take all the knives out of people's backs" (Cameron - Curator); and

- "This vision that our director currently has is cut throat"(Sam - Arts Administrator). The sense of angst described by these administrators suggests that there will be a negative affect on collaboration and relationships between the groups. Sam (Arts Administrator) added that although he felt that the lower level employees in several organisations were friends, the director of his organisation held a 'closed hands' or keep information private policy, which resulted in unwanted tension between them.

In terms of relationships between organisations, artists and other groups, many stakeholders expressed elements of animosity. Sam (Arts Administrator) bluntly admitted that his organisation has "very rocky relationships with some of the local artists." Lisa (Curator) explained how "the conservative artist-run organisations are now finding themselves in competition with others... which are causing friction in the community." Not surprising that most of the artists interviewed agreed that the relationships within the contemporary visual arts community in Cairns were problematic. However to differ from the main perspectives, Kirsty (Artist) did admit that her prior friendships with some of the employees within those organisations had benefitted her relationship.

In regards to the current network systems within the arts sector of Cairns, most stakeholders generally viewed industry network systems as unclear. Many felt that organisations did not appear to work together or with artists. Walter (Council Art Worker) believed, "the intercommunications between networks and organisations in Cairns is not happening" and Annabelle (Member, Regional Arts Development Fund) claimed that, "[Organisations] are operating in their own little areas... I do not hear of much cooperation between the Cairns Regional Gallery and KickArts." Artists on the contrary differ from the organisations with respect to connection building. Artists appear to be linking and networking through social media entirely separately from the organisations and at their own cost and time.

In regards to organisations engaging with artists to present opportunities to exhibit, many of the interviewed artists thought that the organisations did not engage enough. For example, Kirsty (Artist) believed, "they would never go out of their way to grab an artist." In contrast to the views of the artists, representatives in organisations presented as though they were 
actively engaging with artists, and claimed that artists were not approaching them enough. One comment from Tammy (Director, Commercial Gallery) was as follows: "They just need to come and see me... but I am surprised that I do not get approached more." Cameron (Curator) claimed, "I give talks and things... I opened a show at Port Douglas." In fact, some curators interviewed were actively engaging with artists outside of the organisations.

Nevertheless, artists believed that the current levels of engagement were not satisfactory. In relation to engagement, it was surprising that all of the artists answered that they were not actively engaging with the organisations to explore opportunities. Graham (Artist) said, "never. I usually you do not know who they are or where they are" and Cara (artists) replied, "I would not really go up and say hello."

\section{Support, Representation and Grants}

In general, most artists felt that the grassroots local contemporary visual artists were supporting each other. Yet there were some who recognised gaps in other forms of support from the broader arts community. For instance, in relation to the organisations, Cara (Artist) felt that she was "very well supported through the community... [in terms of] artist run initiatives, not so much from the organisations." Differing from this viewpoint, Kirsty (Artist) felt that the support from organisations was not the issue; on the contrary she explained it was the "lack of cultural venues and lack of cultural support" by the public and the council. In relation to who should be supporting Cairns contemporary visual artists, there were mixed views.

Cameron (Curator) who is employed by a council funded gallery presented quite a negative view in regards to support, insisting that the government's bureaucracies are to blame. Cameron explained that support for the arts relied on "a good politician, councilor or mayor [that] will allow things to happen." Lucy (Member, Visual Arts Association) further added that those "who run council [and] do not know anything about art" and "so, how can they make decisions to improve things."

It was perceived by some that there was at one level an element of exclusion. For instance, some believed that non-indigenous artists did not receive the same level of support as indigenous artists. One curator sympathised that:

When there are initiatives or opportunities, there is more of a focus on indigenous artists..." (Lisa - Curator)

Likewise, Cara (Artist) made the comment "unless you're a part of CIAF (The Cairns Indigenous Art Fair ${ }^{1}$ ) then you are faced with lesser support." While it is not the focus of this paper to merit the levels of support for indigenous artists, and in fact there are very valid arguments to continue to strongly promote these artists, it is important in this research to raise the fact that some artists have this view. In addition to views about support for particular artist groups, there was also a perception by one artist that emerging or younger artists may be receiving extra support. Simon (Director, Artist Run Initiative) felt that Cairns Regional Council in relation to opportunities for artists "tends to push for the under thirties... it can be disappointing."

In general, most of the stakeholders agreed that there was arguably never enough funding for visual artists. However, Sam (Arts Administrator) felt that funding in general was creating a

\footnotetext{
${ }^{1}$ CIAF is a three-day art market for commercial galleries and indigenous art centres to sell and showcase art by Queensland Aboriginal and Torres Strait Islander artists.
} 
welfare mentality amongst artists. Regardless of the views about the amount of funding, the artists felt that funds were not being fairly distributed at a local level. Kirsty (Artist) expressed disappointment in funding, in her comment, "I applied for RADF grants... but a lot of the grants went to other people that did nothing... so I never applied again." Clearly, these are only the views of some artists; hence it is very difficult to determine the breadth of such views. At the same time, Cameron (Curator) explains how the RADF (Regional Arts Development Fund) program was established to tackle such issues:

The RADF program started in 1992 ... when the Goss government came in... it was established to address the inequities in arts funding because a vast majority of state government art funding went to the south east Queensland area, so they thought local government would be better to distributing state government arts funding to regionally based individuals and organisations... that created a pool of funds that could be distributed in a democratic way... (Cameron - Curator).

In addition, Annabelle a current member on the board of the Cairns Regional Arts Development Fund, agreed that the program was very good, although did admit that it "could be improved" in terms of the application process.

Other artists perceived that the difficulties and effort involved in applying for grants took time away from creating artwork. One comment included, "For what I see the time and effort involved in the selection criteria is greater than the effort involved in making the paintings...' (Graham - Artist). Graham (artists) also described how artists are not suited to filling out complicated forms and budgets, and suggested simplifying applications or to have a person connecting artists and grants who would aid in career development.

In regards to what areas need attention in order to further support contemporary visual artists in Cairns, some artists mentioned that there needs to be a focus on supplying and subsidising more incubator spaces, that would be available for many artists and not just for emerging artists. One comment included:

"I just really want more opportunities... open up the lane ways and let us create... give us more freedom of space... and bring the level down so its more accessible" (Cara - Artist).

In summary, there are a number of very complex issues that are raised when looking at funding and other support for contemporary visual artists. On the one hand, artists in general have negative views on the time or difficulty involved in applying for funding and being successful in obtaining funding.

\section{Summary and Conclusion}

The key findings of this study can be summarized as follows:

- The literature review demonstrated that a major impediment to developing an artistic career can be a lack of time to engage in artistic practices (Throsby and Thompson 21) This study revealed that a visual artist living and practicing in Cairns had the advantage of having more time to spend on creative practices, as a result of less time commuting for example. This represents a key opportunity for contemporary visual artists based in Cairns.

- Most participants in this study argue there is a lack of networks, industry links and a hub for disseminating/distributing information and/or offering the capacity to develop non-artistic skills. While this is likely to continue in the future, this situation reveals the fact that artists are likely to need to play a more significant role in being enterprising and 
developing their own networks and opportunities, as argued by such authors as Bridgstock ("Not a Dirty Word: Arts Entrepreneurship and Higher Education" 181; "Skills for Creative Industries Graduate Success" 21)

- Access to opportunities to exhibit in Cairns appears limited and in some cases perceptions suggest they are to some extent exclusionary (as described by Ethel, Lucy, Sam and Lisa); as a consequence applications for space are highly competitive.

- As recognised in the literature review (Australia Council 1), artists have difficulties in accessing markets for promotion. Similarly the career development of a contemporary visual artist who lives and practices in Cairns is influenced by the fact that essential lucrative markets and networks appear difficult to access. Specifically, this is due to the following factors:

i) Traveling and transporting artistic goods involves significant distances and hence cost;

ii) Limited funding opportunities exist that support these costs; and

iii) Limited support from organisations is available for touring local artwork.

- As recognised by Youdell and Milledge ("Collective Future" 14), Cairns has the benefits of tourism as a key driver in sustaining a certain level of activity in the production of creative goods. This then proposes opportunities for the visual arts sector to work more closely with those involved in tourism.

- $\quad$ Perceptions from some stakeholders (Kirsty, Ralph, Cara) suggest that there is concern that without support from local council and organisations, careers are less likely to develop any further than the local market; a market that rarely sustains a full-time income.

- As identified by Youdell and Milledge ("Collective Future" 13), many stakeholders reveal that the arts market in Cairns is constantly changing to the influences of the peaks and flows of:
i) government funding;
ii) government ideology;
iii) tourism;
iv) the economy; and
v) council activity.

The results of this study, in general, propose that there are a number of complicating factors at play in terms of the potential for contemporary visual artists to develop a career in Cairns. There are clearly some positives from being based in Cairns (e.g. time to practice) however there are also some significant challenges (e.g. opportunities to exhibit, costs of touring work). The findings also reveal there is much needed research into how networks and industry links can be established to aid career development in relatively isolated regional cites. 


\section{Works Cited}

Australia Council. Artists Career Summary. Queensland: Australia Coucil, 2010. Web. 12 August 2013.

Bridgstock, Ruth. "Not a Dirty Word: Arts Entrepreneurship and Higher Education." Arts and Humanities in Higher Education 12.2-3 (2013): 122-37. Print.

Bridgstock, Ruth. "Skills for Creative Industries Graduate Success." Education \& Training 53.1 (2011): 9-26. Print.

Bystryn, Marcia. "Art Galleries as Gatekeepers: The Case of the Abstract Expressionists." Social Research 45.2 (1978): 390-408. Print.

De Roeper, Julia. "Serving Three Masters: The Cultural Gatekeeper's Dilemma." Journal of Arts Management, Law and Society 38.1 (2008): 51(19). Print.

Mangolte, Babette, et al. "Being Contemporary." PAJ: A Journal of Performance and Art 34.1 (2012): 43-59. Print.

Miles, Matthew B, and Michael A Huberman. Second ed. Californa: Sage Publications Inc., 1994. Print.

Smith, Terry. Contemporary Art: World Currents. London: Laurence King Publishing Ltd, 2011. Print.

Thompson, Maria. Artist. Delhi, India: Global Media, 2007. Print.

Throsby, David, and Beverly Thompson. But What Do You Do for a Living? Redfern: Australia Council, 1994. Print.

Throsby, David, and Anita Zednik. "Multiple Job-Holding and Artistic Careers: Some Empirical Evidence." Cultural Trends 20.1 (2011): 9-24. Print.

Youdell, Rebecca, and Russell Milledge. Collective Future. Unpublished: James Cook University, 2011. Print. 